\title{
Marketing To Health Information Seekers: A Critical Look At The Principal Assumptions
}

S. Altan Erdem, University of Houston-Clear Lake, USA

\begin{abstract}
As the Internet gained more significance in various dimensions of our lives and dealings with others, it was just a matter of time for the world of healthcare to incorporate the Internet-use into its routines. We are now seeing tangible examples of this use in many facets of healthcare industry. Both providers and patients have been pursuing Internet-related strategies, remedies, routines, and etc. for a while now. It has been stated that majority of the Americans who are online are looking for health information. Healthcare information is accessed more than sports, stocks, and shopping. Some believe that this growing use of online health information sources is able to bridge the gap between what patients know and what they are told. In other words, these patients can visit their physicians armed with knowledge obtained on the Web and pursue rather educated discussions with their physicians about their medical issues. Of course, this is true based on the assumptions that the websites that these patients use provide accurate information and the patients comprehend this information properly. The purpose of this paper is to very briefly review some of the ongoing trends in this field and review the practicality of the two assumptions listed above. It is hoped that inquiries like this result in a better understanding of the components required for a proper use of online options to improve the efficiency of healthcare practices.
\end{abstract}

Keywords: Internet; Healthcare Marketing, Online; eHealth Literacy; Information Retrieval; Information Accuracy

\section{INTRODUCTION}

iven that healthcare industry consumes a significant part of the gross domestic product in the U.S., it is not surprising that Internet use has been gaining acceptance within the healthcare industry. Eighty-eight percent of US Internet users in 2010 look for health and medical information online. These users are just a click away from over 100,000 health related websites, government health sites, professional organizations, journals, medical texts, and drug reference books, as well as millions of citations through PubMed, the online search service of the National Library of Medicine. According to comScore Media Metrix, a digital market research company, the first quarter of 2007 witnessed an overall 12 percent growth in the online health information category. The same study reported that the health information category reached an average of 55.3 million visitors (about one third of all U.S. Internet users) per month in the first quarter of 2007 and WebMD Health accounted for 17.1 million of these visitors (Della et al. 2008).

Physician websites have been becoming rather popular in the world of healthcare too (Morahan-Martin 2004). It has also been reported that many of the US physicians are online and spend a significant amount of time researching disease information, drug information, and to a lesser degree, Continuing Medical Education information. Recognizing these trends, the pharmaceutical industry has been increasing its expenditures on Internet drug advertising over the years (Jarvis 2001) as substantially more hospitals have been using the Internet to reach their patients (Fell and Shepherd 2001; Lin et al. 2001). 


\section{INTERNET AND HEALTHCARE}

While there are some potential problems associated with the Internet use in healthcare, there is no doubt that Internet offers numerous opportunities to improve healthcare in general. For eg., a review pharmaceutical marketing on the Internet presents a well-improved picture since customer satisfaction with online prescription drug buying has been rather high (Gurau 2005). On the business management side, many have suggested that Internetbased practice management, catering to physician/patient needs such as completing medical forms, coordinating appointments/referrals, accessing diet/nutrition information, and verifying post-operative care procedures, can gradually minimize the unnecessary back-office management (Kwon and Xie 2003; Shinkman 2000). In addition, having user-friendly websites to address specific healthcare needs benefits both patients and practitioners. Patients are provided with valuable and comprehensive information at low cost. This is very important since it has been reported that many patients do not entirely comprehend the information that they are presented with in the examination room.

It is a well-known fact that physicians have been under increasing financial pressure as reimbursements from managed care and government have been decreasing while malpractice insurance costs have been increasing. Accordingly, they have been reacting to this pressure by seeing more patients daily (Alkhateeb et al. 2009). Unfortunately, this type of practice results in having rather limited time to interact with the patients in the examination room. It has been reported that there are times that patients feel that they are rushed and not given enough time to entirely comprehend the information that they are presented with in the examination room. Recognizing this problem, one would realize that offering an online medical bulletin board offers these patients an alternate outlet to improve their understanding of the issues without having to call their healthcare providers. With complete information available to patients at the click of a mouse, there would be fewer inbound calls made to doctors and that would result in a reduction in overhead for the physician's office in the long run (Goedert 1999; Shepherd and Fell 1998; Shinkman 2000).

\section{CYBERCHONDRIACS}

More people go online for medical advice on any given day than actually visit health professionals, according to figures provided by the American Medical Association. It has been reported that eight out of ten look for health information online, with increased interest in diet, fitness, drugs, health insurance, experimental treatments, and particular doctors and hospitals (Fox 2005). The number of consumers researching pharmaceutical information has tripled during the last five years (Alkhateeb et al. 2008). This increasing popularity of online health access is not limited to the US only. It has been reported that 44 percent of Europeans have been using the Internet for health purposes (Andreassen et al. 2007). This new consumer segment composed of these health information seekers in different parts of the World is what Harris Interactive now calls "cyberchondriacs."

Cyberchondriacs are those who like to use the Internet to educate themselves about their medical conditions. It has been reported that cyberchondriacs are younger (which also fits the profile of frequent Internet users), and more affluent than the general population. Eighty-two percent of them are between the ages 18 and 29, 84 percent of those are with postgraduate degrees and 77 percent of them are with household incomes of over $\$ 75,000$. The 2006 Harris Poll survey results reported that, on average, these users go online to look for healthcare information five times a month, searching mainly through portals or search engines rather than by going directly to particular sites. Based on the 2010 Harris Poll survey, the number of cyberchondriacs leaped from 154 million in 2009 to 175 million in 2010 (88 percent of the US online population). The poll shows that 32 percent of adults say that they regularly look online for health-related information compared to 22 percent in 2009.

These cyberchondriacs believe that once they improve their medical knowledge base by using the online information sources, they will be able to improve the quality of consultation with their physicians. While this is a very reasonable possibility, it is based on two main assumptions that are discussed below. 


\section{ASSUMPTION 1}

The first assumption is about the eHealth literacy of these cyberchondriacs. Specifically, eHealth literacy is defined as "the ability to seek, find, understand, and appraise health information from electronic sources and apply the knowledge gained to addressing or solving a health problem" (Norman and Skinner 2006, p.2). It is assumed that since these cyberchondriacs are believed to be more affluent than the general population, they possess a high level of eHealth literacy. While this is certainly a logical reasoning, one can never be sure of it due to the significant size of the health information volume, as well as the technical and dynamic nature of the information. For instance, one may have a high level of eHealth literacy about a low cholesterol diet but may have a low level of eHealth literacy about thyroid-associated issues.

In order to have a high level of eHealth literacy, one not only has to understand the information but also apply to solve a medical problem properly. In an exploratory study by Pucci (2003), it was stated that 32 percent of health information seekers who obtained medication information from the Internet retained misleading information and failed to apply the appropriate information to solve their problems. It was also noted that 43 percent of those who retained misleading information expressed disappointment when their physicians who refused to prescribe as expected. All these findings suggest that significant portion of cyberchondriacs do not necessarily possess a high level of eHealth literacy and they are really not aware of their lack of eHealth literacy. What is even more frightening is that while these information seekers are supposed to use the health information on the Internet to educate themselves, some of them actually use the same information to not only diagnose their problems but also treat them. It has been reported that as many as 18 percent of these users are diagnosing or treating a medical condition on their own without consulting a doctor (Fox and Raine 2002). Apparently, a serious problem arises when these cyberchondriacs with a low level of eHealth literacy diagnose their own symptoms and then pursue overthe-counter drugs that are not necessarily the best ones for their problems.

\section{ASSUMPTION 2}

The second assumption is about the quality of the health information on the Internet. It has been reported that most people who go online for health information assume that the health information they find is trustworthy (Morahan-Martin 2004). One study reported that 72 percent of those health information seekers believe all or most of the health information online and 69 percent of them state that they have not seen any wrong or misleading health information on the Internet (Morahan-Martin 2004). Interestingly, 2010 Harris Poll survey stated that only eight percent of the respondents believed that the information they found was unreliable. This is rather troubling since many healthcare professionals have been expressing their concerns about the quality of the health information that one can find on the Internet (Eysenbach et al. 2002; McKechnie 1999; Potts and Wyatt 2002). It is a fact that new websites are being developed every day with very little regulation or restriction. Unfortunately the information they provide may often be hard to validate, out-of-date, biased, misleading, or dangerously false (Berland at al. 2001; Bliss-Holtz 1999).

Once again, when these self-diagnosing, self-treating patients fail to see their physicians, they may be relying on incorrect information, resulting in misdiagnosis and inappropriate (perhaps risky) treatment. Some of these patients are increasingly taking responsibility for their health, even going so far as to suggest approaches to their physicians who are sometimes not-too-receptive (Conhaim 2003). The reluctance on the physicians' side is understandable at times. The proliferation and uncertainty around health sites have caused some physicians to distrust anything that a patient might download (Kemper 2001). These physicians are concerned not only about the questionable self-treatments pursued by the patients but also about the future of their relationship with the patients when they have to explain to those patients that their Internet-based information is not as accurate as they thought it was (Kassirer 2000). Understandably patients find themselves in a dilemma when their physician's advice contradicts the information they obtained from the Internet.

\section{ONGOING ATTEMPTS TO MAINTAIN ASSUMPTIONS 1 AND 2}

Improving the eHealth literacy of the cyberchondriacs is a challenging task since it requires each person to recognize his/her limitations when it comes to his/her "ability to seek, find, understand, and appraise health 
information from electronic sources and apply the knowledge gained to addressing or solving a health problem." It is imperative that physicians recognize and embrace the trend that a significant percentage of their patients assume a more active role in maintaining their health and they chose to use the Internet-related tools in process. While some of these physicians may not like the Internet aspect of this trend, they need to accept it since it is the preferred choice of their patients. Once they do that, they should offer some guidelines to those patients about how they can educate themselves in a better way and improve their eHealth literacy. They can easily do that by developing their own websites and presenting a list of links to various dependable websites that they believe their patients should use to gather additional information to educate themselves properly.

Improving the quality of the healthcare information on the Internet is even more challenging task since there is no third-party government agency to oversee the practices of health information sites. This questionable quality of health information online has been a major concern for a long while and it recently led the U. S. Department of Health and Human Services to include an objective in their Healthy People 2010 publication to "increase the proportion of health-related World Wide Websites that disclose information that can be used to assess the quality of site." Even though there are no federal regulatory agencies over these websites, there have been various efforts taken by certain groups to supervise the medical information on the Internet to some degree. Some of the most common parties and/or attempts are Health on the Net (HON) Foundation and Utilization Review Accreditation Commission (URAC). Both HON and URAC are independent, nonprofit monitoring organizations that examine numerous issues such as privacy and security, disclosure, development and revision of content, links to other websites (and credibility of those sites), etc. If a website subscribes to the voluntary code of standards established by HON and URAC, it is allowed to display the HON and URAC seals that are recognized as "seals of approval."

While these are very worthwhile attempts, unfortunately these foundations are not able to serve as regulatory agencies since they do not have formalized power in the industry. Therefore, it is a very good strategy for those cyberchondriacs to start their search by using sites such as www.healthratings.org, a joint project of Consumer Reports Web Watch (a non-profit publisher of Consumer Reports) and the Health Improvement Institute (a non-profit, charitable organization) that rates various health-related websites by using a rigorous criteria based on numerous credibility guidelines and editorial adequacy. It is hoped that as these unique consumers/patients get more educated in terms of these types of organizations, they begin to narrow their online search to those websites that have the right credentials. By this way, not only they will be able to improve their eHealth literacy properly, but also those websites with questionable information (and lack of credentials) will eventually be dropped from the search engines and lose their share of the Internet volume.

\section{CONCLUDING REMARKS}

Even though there are serious and legitimate concerns about the eHealth literacy of the online health information seekers and the accuracy of the online health information, it is still true that the healthcare practices can benefit significantly from the resources provided by the Internet. After all, the Internet technology has the potential to improve the efficiency in the marketplace and provide the patients with additional options and more interactive choices. In addition, there are numerous sources for patients to use to improve their knowledge base as long as they take the time to examine the legitimacy and the credibility of the healthcare websites that they are using. Once they do that, they can narrow their online search, access better websites with more accurate health information, and improve their eHealth literacy. They just need to understand that for the time being, they should use the health information on the Internet as an additional source as opposed to a primary one.

It is hoped that studies such as this one will help in speeding up the process of creating a better environment composed of better educated parties and more informative choices for them. Only then, we can truly enjoy the tangible benefits of the interactive practices on the Internet in healthcare industry.

\section{AUTHOR INFORMATION}

Dr. S. Altan Erdem received his Ph.D. in Marketing from the University of North Texas in 1991. Currently he is a Professor of Marketing and the Marketing Program Coordinator at the University of Houston-Clear Lake. Dr. 
Erdem has published numerous articles in various academic journals, textbooks, international and national conferences. His current research interests include healthcare marketing, online marketing applications, and marketing channels.

\section{REFERENCES}

1. Alkhateeb, Fadi M., Khanfar, Nile M., Doucette, William R., and Loudon, David (2009) "Characteristics of Physicians Targeted by the Pharmaceutical Industry to Participate in E-detailing," Health Marketing Quarterly, Vol. XXVI, 98-116.

2. Alkhateeb, Fadi M., Clauson, Kevin A., Khanfar, Nile M., and Latif, David (2008), "Legal and Regulatory Risk Associated with Web 2.0 Adoption by Pharmaceutical Companies," Journal of Medical Marketing, Vol. VIII (4), 311-318.

3. Andreassen, H. K., Bujnowska-Fedak, M. M., Chronaki, C. E., Dumitri, R. C., Pudule, I., and Santana, S. (2007), "European Citizens' Use of E-health Services: A Study of Seven Countries," BMC Public Health, Vol. VII, 53.

4. Berland, G. K., Elliott, M. N., Morales, L. S., Algazy, J. I., Kravitz, L. R., Broder, M. S., Kanouse, D. E., Munoz, J. A., Puyol, J. A., Lara, M., Watkins, K. E., Yang, H., and McGlynn, E. A. (2001), "Health Information on the Internet: Accessibility, Quality, and Readability in English and Spanish," Journal of the American Medical Association, Vol. CCLXXXV, 2612-2638.

5. Bliss-Holtz, James (1999), "Editorial: The Nurse, the Internet, and Consumer Protection," Issues in Comprehensive Pediatric Nursing, Vol. XXII (4), 3-7.

6. Conhaim, Wallys W. (2003), "Is the Doctor Online?” Link-Up@ Home: Your Personal Guide to the Web, Information Today, (February), 29-31.

7. Della, Lindsay J., Eroglu, Dogan, Bernhardt, Jay M., Edgerton, Erin, and Nall, Janice (2008), "Looking to the Future of New Media in Health Marketing: Deriving Propositions Based on Traditional Theories," Health Marketing Quarterly, Vol. XXV (1/2), 147-174.

8. Eysenbach, G., Powell, J., Kuss, O., and Sa, E. R. (2002), "Empirical Studies Assessing the Quality of Health Information for Consumers of the World Wide Web: A Systematic Review, Journal of the American Medical Association, Vol. CCLXXXVII, 2691-2700.

9. Fell, Daniel and Shepherd, C. David (2001), "Hospitals and the Web: A Maturing Relationship," Marketing Health Services, (Summer), 36-39.

10. Fox, S. (2005), Health Information Online: Eight in Ten Internet Users Have Looked for Health Information Online, with Increased Interest in Diet, Fitness, Drugs, Health Insurance, Experimental Treatments, and Particular Doctors and Hospitals. Washington, D.C.: Pew Internet \& American Life Project.

11. Fox, S. and Raine, L. (2002), Vital Decisions: How Internet Users Decide What Information to Trust When They or Their Loved Ones are Sick. Washington, D.C.: Pew Internet \& American Life Project.

12. Goedert, Joseph (1999), "Partners Healthcare System Uses the Internet to Integrate Its Delivery System and Foster Collaboration Among Physicians,” Health Data Management, (December), 27-35.

13. Gurau, Calin (2005), "Pharmaceutical Marketing on the Internet: Marketing Techniques and Consumer Profile," Journal of Consumer Marketing, Vol.XXII (7), 421-428.

14. Jarvis, S (2001). "Scripted Response," Marketing News, Vol. XXXV (8), 3-4.

15. Kassirer, J. (2000), "Patients, Physicians, and the Internet," Health Affairs, Vol. IX (6), 115- 123.

16. Kemper, Donald W. (2001), "Trust on the Health Internet," Managed Care Quarterly, Vol. IX (1), 9-18.

17. Kwon, Ik-Whan G. and Xie, Henry Y. (2003), "Internet Use by Physicians and Its Impact on Medical Practice-An Exploratory Study," Health Marketing Quarterly, Vol. XXI (1/2), 5-27.

18. Lin, B., James, K., Vassar, J., and Martin, C. (2001), "The Internet and Hospital Marketing Strategy: A Survey," Health Marketing Quarterly, Vol. XVIII (3/4), 27-37.

19. McKechnie, S. (1999), "Health on the Internet: A Mix Blessing," Consumer Policy Review, Vol. IX (3), 86-91.

20. Morahan-Martin, Janet M. (2004), "How Internet Users Find, Evaluate, and Use Online Health Information: A Cross-Cultural Review," CyberPsychology \& Behavior, Vol. VII (5), 497-510.

21. Norman, C. D, and Skinner, H. (2006), "eHealth Literacy: Essential Skills for Consumer Health in a Networked World," Journal of Medical Internet Research, Vol. VIII. 
22. Potts, Henry W. and Wyatt, Jeremy C. (2002), "Survey of Doctors' Experience of Patients Using the Internet," Journal of Medical Internet Research, Vol. IV (1), 29-34.

23. Pucci, E., "Is the Internet Transforming the Physician-Consumer Relationship? Preliminary Data in a Neurological Setting," European Journal of Neurology, Vol. X, 2003, 192.

24. Shepherd, C. D. and D. Fell, D. (1998), "Building Web Sites that Attract Visitors," Marketing Health Services, (Spring), 44-45.

25. Shinkman, Ron (2000), "Back-Office, Online," Modern Healthcare, (January), 46. 